\title{
Entre subjetividad y alteridad en el discurso político en prosa de Gabriela Mistral en la década de 1930
} Entre subjetividade e alteridade no discurso político
em prosa de Gabriela Mistral na década de 1930

\section{Between subjectivity and otherness in Gabriela Mistral's political discourse} in the form of prose during the decade of 1930

Esse artigo é o resultado parcial de uma pesquisa que recebeu financiamento da Fundaçą Amparo à Pesquisa do Estado do Amazonas.

Professor da Universidade de Santiago do Chile e da Universidade Chileno-Britânica (Santiago, do Estado do Amazonas. Licenciado em Letras Inglês pela Universidade de Santiago Chile. E-mail: gabrielfariasrojas@gmail.com

Doutora em Linguística pela Universidade Federal da Paraíba (UFPB), Mestre em Linguística Aplicada pela Universidade do Vale do Rio dos Sinos (UNISINOS). Professora do curso de Letras da Universidade do Estado do Amazonas (UEA). Aualmente, coordena o referido PPG. E-mail: jucianecavalheiro@gmail.com
Gabriel Arturo Farias Rojas 2 Universidade de Santiago do Chile e Universidade Chileno-Britânica, Santiago, Chile. Juciane dos Santos Cavalheiro ${ }^{3}$ Universidade do Estado do Amazonas, Manaus, AM, Brasil.

RESUMEN: El artículo se propone realizar análisis crítico sobre el discurso político de Gabriela Mistral, operando desde la descolonización de mito creado sobre ella, el cual habrá abierto nuevas miradas al entendimiento de nuestra primer Premio Nobel de Literatura, tanto en Chile como en el resto de los pueblos de Iberoamérica. Para este artículo, fueron seleccionados dos textos en los cuales se revela cómo Gabriela Mistral entendía a una de las más emblemáticas figuras para la América hispánica, a saber, Simón Bolívar. Ambos textos fueron publicados en el periódico El Mercurio en 1931: "Bolívar a los 40 años" y "La Ambición de Bolívar". En términos generales, tratan sobre un perfil biográfico. Sobre estas composiciones incidirá, no la Mistral ideológica, sino la cronotópica, aquella sobre la cual se abre un resplandor de subjetividad. No pesará sobre su memoria la falsificación político-biográfica tradicional. Por otro lado, se revelará una nueva narrativa sobre ella, lo que ayudará a mostrar una globalidad alternativa de la autora: la política. Sin embargo, esta nueva narrativa será perceptible como la dinámica de un cronotopo en constante inacabamiento, lo que suspenderá esa biografía monolítica de una Mistral apolítica y conservadora, impuesta desde el mito colonial del Chile Republicano.

Palavras-clave: Alteridad; Discurso Político; Gabriela Mistral; Subjetividad.

RESUM0: 0 artigo se propõe a realizar análise crítica sobre o discurso político de Gabriela Mistral, operando desde a descolonização do mito criado sobre ela, o qual terá aberto novos olhares ao entendimento de nossa primeira Nobel de Literatura, tanto do Chile quanto do restante das Américas Ibéricas. Para este artigo, foram selecionados dois textos em que se revela como Gabriela Mistral via uma das mais emblemáticas figuras para a América Hispânica, a saber: Simón Bolívar. Foram ambos publicados no periódico El Mercurio, em 1931: "Bolívar a los 40 años" e "La Ambición de Bolívar". Em termos gerais, eles tratam sobre um perfil biográfico. Sobre estas composições incidirá, 
não a Mistral ideológica, mas a cronotópica, aquela sobre a qual se abre um clarão de subjetividade. Não pesará sobre sua memória a falsificação político-biográfica de Mistral. Por outro lado, revelará uma nova narrativa sobre ela, o que ajudará a mostrar uma globalidade alternativa da autora: a política. Porém, essa nova narrativa será perceptível como a dinâmica de um cronotopo em constante inacabamento, o que suspenderá essa biografia monolítica de uma Mistral apolítica e conservadora, imposta desde o mito colonial do Chile Republicano.

Palavras-chave: Alteridade; Discurso Político; Gabriela Mistral; Subjetividade.

ABSTRACT: This article consists of doing a critical analysis of Gabriela Mistral's Political Discourse in order to decolonize the myth created about her, as this will open new perspectives about the understanding we have of our First Nobel Prize in Literature in both Chile and the rest of the countries in Iberian America. For this article, two texts were selected in which it is revealed how Gabriela Mistral reflected on one of the major figures in Hispanic America, namely Simón Bolívar. Both of them were published in the newspaper El Mercurio in 1931: "Bolívar a los 40 años" and "La Ambición de Bolívar". In general terms, they deal with a biographical profile. In addition, the focus will not be on the ideological side of Mistral, but on her chronotope, the one which allows us to have access to her subjectivity. Thus, on the one hand, the traditional manipulation of Mistral's political biography will not weigh upon her memory. On the other hand, the consideration of her chronotope will reveal a new narrative about her, and this will prove useful as an alternative understanding of the author. Nonetheless, this will take place from this facet censored in her literary writing, i.e. the political writing published out of her homeland. However, this new narrative will be a chronotope that will see its own completion in a continuum, since this never-ending process will help to suspend this monolithic biography of an apolitical and conservative Mistral, imposed since the advent of the colonial myth of the Republic of Chile.

Keywords: Gabriela Mistral; Subjectivity; Otherness; Political Discourse

\section{Introducción}

Hipro discurso literario-político de Gabriela Mistral será entendido como la producción discursiva escrita cuyo contenido principal sea el político. En primer lugar, es necesario entender el discurso como producto de un proceso de enunciación y, en este caso, el de comprender el enunciado producido por el sujeto, Gabriela Mistral, con respecto al contexto sociopolítico internacional de la década de 1930 y a interlocutores concretos, siendo estos últimos los lectores del diario El Mercurio.

Es un hecho que todo discurso, de la naturaleza que sea, tendrá siempre una entre dos intenciones posibles por parte de su autor; a saber, el texto tenderá a ser literal o literario, sin jamás serlo unitariamente de forma tajante entre ambas opciones. Así, es menester entender el proceso discursivo desde el discurso, quien lo produce, y a quién se refiere dicho discurso. De la misma forma, la literatura jamás pesará sola sobre el discurso, justamente por el carácter eminentemente gregario y su composición, lo que lleva a la conclusión de que un discurso literario será literario-político, literario-antropológico, literario-fotográfico, etc., y jamás sólo literario. Así pues, al estar ante los escritos políticos de la primera Nobel de Literatura, se estará ante escritos de naturaleza política, pero que lo serán eminentemente literarios. Asimismo, el mero hecho de escribir una ficción biográfica o semibiográfica, por ejemplo, a quien fue dada el propio nombre o el nombre de 
quien es referido en el texto no hará, en ningún caso que dicha biografía ficcional o ficción biografiada sea eminentemente biográfica o ideológica, en desmedro de una creación literaria.

Este discurso será político, debido al hecho de estar constituido por signos linguísticos de naturaleza ideológica, los cuales se realizan semánticamente en el curso del proceso enunciativo en el cual son concebidos. Ellos tienen carga valorativa por parte de la autora y responden a procesos históricos determinados. En la línea de la realización semántica de la prosa política mistraliana, Carlos Alberto Faraco afirma lo siguiente sobre la semántica y su historicidad:

cada uma dessas várias semânticas se articula, organiza sua arquitetônica (aproveitando um termo e conceito do Bakhtin dos primeiros textos), nos processos de atribuição de diferentes valores aos entes e aos eventos, às ações e às relações do vasto espectro das experiências históricas de qualquer grupo humano e decorrem da heterogeneidade dessas experiências (FARACO, 2017, p. 52).

Se desprende de lo expuesto que, además del proceso enunciativo y de las características semánticas del discurso político de Mistral, el cual responde a un contexto histórico, ese discurso es subjetivo y heterogéneo, es decir, varía según los temas, los interlocutores, vida del locutor / enunciador, del tiempo histórico en que ese discurso es presentado y del lugar en el cual él es expresado.

Para este artículo, fueron seleccionados dos textos contenidos en Gabriela Mistral: escritos políticos ${ }^{1}$. Traemos la posición de Mistral acerca de una de las figuras emblemáticas para los hispanoamericanos: Simón Bolívar (Venezuela, 1783 - Colombia, 1830). Los dos discursos fueron publicados

\footnotetext{
${ }^{1}$ Obra publicada en 1994 por el Fondo de Cultura Económica, tanto en Chile y México. El editor de la obra, Jaime Quezada, es un reconocido poeta chileno e investigador de la obra poética y prosaica de Mistral. Es presidente de la Fundación Premio Nobel Gabriela Mistral.
}

en el diario El Mercurio, en 1931: "Bolívar a los 40 años” y "La Ambición de Bolívar". En el texto de Quezada (1994), se presentan como "Bolívar (I)” y "Bolívar (II)" respectivamente. En términos generales, tratan sobre un perfil biográfico.

\section{Cronotopo mistraliano en la década de 1930: Mistral y el latino-americanismo hispano-americano}

La consideración de tiempos históricos en la construcción de nuestro relato de una biografía política de Gabriela Mistral, a través del estudio de su discurso político, que considera una subjetividad descentrada, es decir, variada y, debido a ello, nunca objetiva o estática, es mejor comprendida a través de la idea de cronotopo desarrollada por Mijaíl Bajtín. En Estética da criação verbal, Bakhtin confiere, al Viagem à Itália 1786-1788, de J. W. Goethe, la responsabilidad de expresar diegéticamente la subjetividad de su autor, convirtiéndola en la materia prima para la operación que vendrá a promover la intersección entre el tiempo y el espacio en la formulación de uno de sus más ingeniosos conceptos, a saber: el cronotopo. José Luiz Fiorin, respecto a la naturaleza del cronotopo, explica que,

Os textos literários revelam-nos os cronotopo de épocas passadas e, por conseguinte, a representação do mundo que tinha a sociedade em que eles surgiram. Figura-se o mundo por meio de cronotopo, que são, pois, uma ligação entre o mundo real e o mundo representado, que estão em interação mútua. 0 cronotopo brota de uma cosmovisão e determina a imagem do homem na literatura. A relação entre espaço e tempo é indissolúvel. 0 cronotopo é uma categoria conteudístico-formal, que mostra a interligação fundamental das relações espaciais e temporais, representadas nos textos, principalmente literários (FIORIN, 2017, p.145)

A partir de la idea de cronotopo, proponemos estructurar nuestra narrativa de Gabriela Mistral como sujeto político en un tiempo determinado 
ligado a un lugar y contexto específicos. En ese sentido, fue escogido un periodo de tiempo que da cuenta de una Mistral que, en la década de 1930, tenía una mirada y una preocupación latinoamericana desde una concepción hispanoamericana.

La elección de la década de 1930 no es aleatoria. El objetivo de este trabajo, cuya naturaleza de investigación es cualitativa e inductiva - debido a que una hipótesis colocaría un centro en un sujeto que queremos rescatar de la prisión en que el mito colonial republicano la tiene -, es liberar a Gabriela Mistral de la concepción clásica, monolítica y conservadora en que se encuentra con el objetivo de servir a los propósitos de un sistema del cual ella tuvo que huir para realizarse en la escritura libre y pensante que demostró alrededor del mundo. En este sentido, no interesa para el objetivo mencionado hablar más acerca de ella dentro de los límites geográficos de Chile. Lo relevante para este trabajo es el estudio del discurso inicial que desarrolla después de sus primeras experiencias fuera de su tierra natal.

Creemos que, para derribar el mito colonial de tipo republicano, el cual emula una colonización de corte europeo desde una réplica discursiva por parte de la clase alta nacional, hay que regresar a nuestro origen, fuente de nuestra identidad democrática, es decir, nuestra independencia. Para ello, se debe considerar la liberación desde nuestra identidad dialógica y enunciativa, es decir, desde la identidad latinoamericana y no una nacionalista. Por eso, hay que enfocarse en una Mistral que, aunque nunca le dejó de importar su patria, tenga una mirada latinoamericana y una perspectiva mundial, que la libere del status quo de la política republicana chilena y, junto con ello, de la censura que el discurso letrado republicano y las políticas represivas de la época impusieron en su escritura dentro del territorio nacional.

Con dos escritos sobre Simón Bolívar, Gabriela Mistral hace una profunda reflexión sobre lo que significa ser latinoamericano desde la identidad hispanoamericana. Esta identidad tiene que ver con el proceso de descolonización y liberación de los españoles por parte de los pueblos en los países latinoamericanos de habla española. Así, en la década de 1930, Gabriela Mistral intenta rescatar el mito del origen latinoamericano, mito sobre lo que significa ser latinoamericano para el pueblo - y no para la burguesía. Sin embargo, este origen tiene características muy especiales. Por un lado, ese mito tiene relación con el mestizaje y reivindicación de los pueblos originales de América. Por otro lado, la reivindicación de esos pueblos excluidos dialoga con sus luchas - de liberación, independencia.

En este recorrido por el cronotopo identitario en América Latina e Hispanoamérica, es bueno recordar que Mistral publicó su obra poética Tala en el año 1938. Es una escritura endógena que, una vez más, reivindica el origen y la identidad de los pueblos hispanoamericanos en un período de vanguardias y miradas a una Europa siempre colonizadora, siempre letrada. ${ }^{2}$

\subsection{La ambición de Bolívar}

De la misma manera en que ella se refiere a personajes importantes de la historia latinoamericana, otros escritores también han hablado sobre Bolívar. Mistral, sin entregar nombres, habla en términos generales del daño que ellos han hecho a la figura de Simón Bolívar. En ese sentido, una de las causas que motiva la defensa que ella hace del prócer es la de la ambición que ha sido referida como una característica negativa en Simón Bolívar. Al respecto, Gabriela Mistral afirma lo siguiente:

Los escritores que malquieren a Bolívar insisten mucho en su ambición la sacan a lucir como una medida mañosa que le rebaje hasta la mitad de la estatura y la revuelven con la palabrita hasta que echa sobre el hombre unas luces sesgadas.

2 Entendemos "letrada" desde la imposición de un canon literario. 
Hasta donde se toca ambición se tiene tacto leal de hombre; cuando ya no se la toca, la criatura se vuelve nada menos que el santo y produce no sé qué vértigo (MISTRAL, 1931, p. 200).

Las palabras anteriores son el reflejo fiel no sólo de una opinión sino también de la propia experiencia de la autora, debido al hecho de haber sufrido las consecuencias de una canonización prematura que la hizo salir de Chile para encontrar, de cierta forma, su libertad. De esta manera, la necesidad de los escritores y biógrafos de encontrar una narrativa objetiva, lineal y global de la vida de una persona hace que, a menudo, distorsionen la memoria de esa persona.

La astucia de Mistral consiste en no negar la ambición de Bolívar, sino en reivindicar su lado positivo en la biografía del autor. En ese sentido, sus palabras desafiantes dicen:

Ambición natural la que llevó y mostró, tan natural como su corazón vivo y lleno de sangre que buscaba empleo, tan natural como que comiese y llevase ropas, ¿qué querían, pues, los hipocritones? Un santo-general no se ha visto y menos un libertador de un continente de tierra y agua (MISTRAL, 1931, p. 200).

Un santo en oposición a la libertad deja en claro que la canonización temprana de una figura la encarcela en una biografía injusta, la cual tiene más vacíos que certezas. Así, de la misma manera en que un santo se alejaba de la ambición, Simón Bolívar era juzgado por el hecho de no ser un santo. Esto significa que si él no puede ser un santo-general, es, entonces, un libertador-general, es decir, un hombre combatiente. De ahí que esas palabras mistralianas sean tan importantes y relevantes, debido a concordar con el principio bolivariano asumido por el libertador antes de escribir el Manifiesto de Cartagena en el año 1812. Según Néstor Kohan, "poco antes de escribir su manifiesto, Bolívar había llegado a una conclusión taxativa: 'la guerra, sólo la guerra puede liberarnos de los tiranos odiosos y desleales'." (KOHAN, 2013, p. 125).

Sin embargo, la ambición en tanto negatividad se atribuía a Bolívar debido a su origen burgués como también por la educación de élite que recibió. Por ello, Mistral, del otro lado de la moneda, es decir, el de quien enuncia desde un origen humilde, una vez confirmando esa ambición, pero desde la aprobación, explica el porqué de la ambición del Libertador en la siguiente expresión:

La ambición de Bolívar después de nacer en la familia donde nació, de recibir el legado casi bautismal del canónigo Aristiguieta y de vivir en cortes europeas que llegaron a parecerle domésticas, debía volver la cara inteligente hacia lo único que le faltaba, que era la gloria. Poseía la mirada panorámica, así para la geografía como para la historia y con este ojo de beber masas y de coger volúmenes él vio que ella le faltaba para sentirse completo, que es como les gusta sentirse a los héroes y a los santos. Bienhaya su "vistazo" y su determinación, bienhaya por él y por nosotros (MISTRAL, 1931, p. 200-201).

Aquí hay tres puntos a analizar en profundidad. El primero de ellos es que efectivamente Bolívar, así como es expresado por Mistral, provenía de una clase privilegiada. En realidad, no era sólo una clase privilegiada sino una de las más acomodadas del período colonial. De ahí que sea mencionado ese legado canónico por Gabriela Mistral además de los viajes que él hizo a Europa. Esta clase social a la que Bolívar pertenecía era llamada de Mantuanos y, para poder entender sus características y, sobre todo el legado, especialmente, en términos económicos, con el que Bolívar fue beneficiado, es necesario citar en extenso a Kohan:

La familia Bolívar es de origen vasco. El primero de todos, que también se llamaba Simón, viajó a América en 1559. Su apellido original se escribía "Bolíbar", del cual luego cambia la "b" por la "v". Como recuerda Juvenal Herrera Torres en su obra Simón Bolívar, vigencia histórica y política, 
el papá de Simón dejó de herencia a sus cuatro hijos (dos varones, Juan Vicente y Simón, y dos mujeres, Juana y María Antonia): 258.000 pesos en dinero. Dos plantaciones de cacao, cerca de Caracas. Cuatro casas en Caracas, con los esclavos, muebles y joyas correspondientes. Nueve casas en la Guaira. Objetos de plata valorizados en 46.000 pesos. Una casa de campo a orillas del mar. Casa y finca fueron del recinto de Caracas. La finca de San Mateo, con más de 1.000 esclavos (es probable que esta cifra sea un tanto exagerada, otros autores mencionan 160 esclavos) y dos trapiches azucareros. Un rancho de producción de índigo cerca de San Mateo, en el valle de Aragua. Tres extentísimos ranchos de ganado de vacuno en los llanos, hacia el Orinoco. El valle de Arroa, con minas de cobre, y las minas de Cocorote. Su origen de clase resulta inequívoco, lo vincula a la oligarquía criolla de Caracas, una elite conocida como "mantuana" por los elegantes mantos que usaban sus mujeres. Este sector social había acumulado tanta riqueza que se sentía superior incluso a los españoles recién llegados de la península ibérica, fueran éstos militares o civiles (KOHAN, 2013, p. 82-83).

De este modo, no hay cómo negar el origen de clase alta de Bolívar. Pero el segundo de los puntos - es decir, su origen privilegiado - a ser esclarecidos ayuda a entender más el primer punto - su ambición - debido al hecho de que se rebeló ante su clase social, ya sea por su sed de gloria o de justicia social. Esto hace de él no un santo - porque los santos no son ambiciosos - sino un héroe. Es por este motivo que Mistral agradece su ambición de gloria, es decir, una ambición de gloria de liberación, deseo de todos los colonizados y víctimas de la injusticia social.

También, el tercero de los puntos es el legado bautismal y canónico por él recibido, pero por él mismo rechazado poco después. Confirmando la ironía de Mistral, las siguientes letras sobre el Manifiesto de Cartagena son evidentes:

... en su Manifiesto de Cartagena (1812), Bolívar había caracterizado a los cardenales, arzobispos, obispos, canónigos y clérigos opuestos a la independencia y revolución como "tránsfugas". En ese documento afirmó sin ambigüedades que "la profesión de toda la jerarquía eclesiástica y los grandes de España es el dolo y la intriga". Sus numerosas disputas con las altas jerarquías de la Iglesia católica estaban mediadas no tanto por sus vínculos y simpatías masónicas (comunes a la mayoría de los revolucionarios independentistas de Nuestra América) sino por la bula del Papa Pío VII, que en abierta defensa del colonialismo europeo, condenaba a los revolucionarios que se animaban a desafiar al imperio (KOHAN 2013, p. 131).

Así, el héroe de Gabriela Mistral era un héroe cuya ambición significaba que él tenía que rebelarse contra poderes contrarrevolucionarios de la época, tales como la Iglesia Católica. Esto era no sólo ir contra la iglesia sino también contra el legado que recibió desde niño, el cual era motivo de heroísmo debido a que él tuvo una conciencia social superior. El motivo de ello era que, aun no creyendo en Dios, no estaba contra la religión sino contra la élite de la Iglesia Católica que defendía el colonialismo. La prueba de esto fue el hecho de que él admirase al padre Bartolomé de las Casas, quien fue calificado por Bolívar como un "héroe" (KOHAN, 2013, p.133), el mismo calificativo usado por Mistral para describir Bolívar.

Es de tener en cuenta, el uso y abuso que la Iglesia hacía de la excomunión como castigo más grave para los libertadores de América. La forma eminentemente política de una exclusión que debía responder a un asunto meramente religioso es criticada en duros términos por Bolívar, quien no demuestra suavidad ninguna para referirse a la élite eclesiástica amiga de los enemigos españoles y, por este motivo, se convertía también en enemiga de los y las colonizados(as). Kohan consigna esta crítica en la cita abajo:

... el Libertador dirá a Perú De Lacroix: "Yo no puedo recordar sin sonreírme cómo me excomulgaron a mí, junto con todo mi ejército. Los prelados Pey y Duquesne, que dirigían la arquidiócesis de Bogotá el 3 de diciembre de 1814, afirmaban que yo iba a despojar a la iglesia, a perseguir a los sacerdotes, a destruir la religión, a violar a las vírgenes, a mutilar a los hombres y a los niños. Todo esto fue públicamente refutado con otro 
edicto, en el cual se me presentaba ya no como hereje y sin Dios, como en el primer edicto, sino como bueno y católico ortodoxo! ¡Qué estúpida farsa y qué lección para el pueblo! Nueve o diez días separaban estos dos edictos. El primero fue publicado porque yo entraba a Bogotá por orden del Congreso, y el segundo porque yo entré victorioso a la capital (KOHAN, 2013, p. 131-132).

Lo anterior evidencia no sólo una situación injusta sino también una verguenza, debido a que una herramienta tan delicada como la excomunión era aplicada como abuso de poder. El ejemplo mencionado por Bolívar es realmente patético, pero no representativo del clero popular, como en el caso de Bartolomé de las Casas. Como consecuencia, Bolívar, aun no creyendo en Dios, respeta la religión del pueblo más allá de las diferencias con la burguesía eclesiástica.

El respeto por la convicción católica de las personas tiene que ver con la naturaleza democrática del Libertador. La misma Mistral exclama que en su ambición "se le fueron encandilando muchas cosas", siendo uno de ellas el hecho de "el ver hacerse a Napoleón como un árbol de esos que los magos ponen a crearse en unas horas” (Mistral, 1931, p. 201). Aquí Mistral quiere develar la verdadera ambición de Bolívar en oposición a aquella otra ambición, como la de Napoleón. Mientras Napoleón buscaba expandirse a través de la colonización, es decir, a través del expansionismo puro, Bolívar, por su parte, buscaba la concreción de un proyecto internacionalista, de unión de diversos estados a través de la cooperación y no de la supremacía de un país por sobre los otros.

Quedando manifiesto el por qué la ambición de Bolívar no era la de un victimario sino aquella de un héroe latinoamericano, Gabriela Mistral dice que "en vez de contarle y medirle la ambición - con cierta manita peluda de murciélago -, mejor sería darse cuenta de cómo ella fue metal químicamente puro, o mejor una especie de agua súper filtrada en la que no se quedó bailando una arenita oscura, una hilacha de dineros, una pajita sospechosa de medro" (MISTRAL, 1931, p. 201). Es finalmente esa descripción de un ser ambicioso y heroico al mismo tiempo, es decir, digno de ser admirado, a lo que corresponde la capacidad de Bolívar de rechazar siempre la posibilidad de convertirse en una especie de rey criollo. El mismo Bolívar expresa su convicción democrática y leal con el pueblo al respecto en carta a Santander el 21 de febrero de 1826, al afirmar que: "según estos señores, nadie puede ser grande, sino a la manera de Alejandro, César y Napoleón. Yo quiero superarlos a todos en desprendimiento... mi ejemplo puede servir de algo a mi patria misma pues la moderación del primer jefe cundirá entre los últimos y mi vida será su regla..." (KOHAN, 2013, p.270). De esta manera, el proyecto de Bolívar, y de la misma Gabriela Mistral, es un proyecto éticopolítico, de una república moral que pueda descolonizar al pueblo gracias a la unión de los colonizados en la lucha por su liberación. Ese proyecto es tanto ambicioso como revolucionario, pero siempre democrático.

\subsection{Bolívar a través de su cuerpo}

En el recorrido de la aventura bolivariana, Gabriela Mistral analiza la vida del Libertador por medio de aspectos tales como sus arrugas, su mirada o su frente. Eso es una importante reflexión sobre los efectos de las vivencias en una persona. Básicamente, el relato puede decir mucho acerca de Bolívar, pero su cuerpo y sus partes son el relato vivo de cómo el Libertador sintió el proceso de emancipación latinoamericana con sus alegrías, victorias, decepciones y derrotas. Así, y como parte del cuerpo de Simón Bolívar, su rostro es usado por Gabriela Mistral para escribir una suerte de biografía de él al comenzar diciendo que,

El rostro cuarentañero de Bolívar es y será siempre uno de los que más intriguen en la escenografía americana, cosa muy diversa de la placidez sonrosada de Washington y menos feo, pero no menos patético que el de 
Lincoln. No tiene más de cuarenta años, y las arrugas le hacen una reja de prisionero, y la prisión es verdadera y corresponde a la fatiga y al desengaño que por fin le han atrapado, Las arrugas lo trabajan de dentro afuera, al revés de los demás hombres maduros. A los otros les estropea la edad y a éste el corazón, su enemigo, el clavo de adentro que no se puede despuntar (MISTRAL, 1931, p. 196).

La ironía mistraliana acerca de la "placidez sonrosada de Washington" o la cara patética de Lincoln tiene que ver con el hecho de que han sido representantes del Liberalismo, ideología abrazada en América del Norte, principalmente en los Estados Unidos, que, aunque históricamente ha estado relacionada con la libertad, es en el fondo una libertad entendida desde la metonimia de un grupo específico de personas y elitista y otro subordinado completamente a los intereses de esa élite. Es innegable el hecho de la esclavitud mucho tiempo después de la independencia de Estados Unidos. Además, detrás de los rostros de sus presidentes supuestamente democráticos, estaba el deseo y la práctica misma del expansionismo, todo lo contrario a la Patria Grande de Bolívar. De ahí que este último se describiera en oposición a los presidentes norteamericanos.

También, de la manera en que en el subcapítulo anterior se hace referencia a la ambición positiva de Bolívar, Mistral deja patente el hecho de que él está preso en su misión. Es un círculo en el que busca la independencia de América Latina de los constantes enemigos que nunca acaban. Además, esas arrugas que provienen desde el interior de su cuerpo, podrían ser interpretadas alegóricamente como una genética de la Liberación que no sólo se desarrolla mirando al futuro, sino que tiene una memoria que proviene de todos los héroes que lucharon por la liberación de los pueblos latinoamericanos. Un ejemplo de ello podría ser la revolución indigenista de Tupac Amaru II y la fuente de inspiración que ello significó para las sucesivas luchas por la emancipación de los pueblos del continente americano (KOHAN, 2013).
Una vez aclarada esa experiencia de generaciones que heredaron el legado de Bolívar, Mistral se refiere a la importancia de la mirada de Bolívar. De esta manera, las palabras dedicadas al Libertador son las siguientes:

¿Quién no querría ver la mirada de Bolívar y repartírsela en este momento? Las mujeres desearíamos que nos diera la que daba a Teresa de Toro; los muchachos le pedirían la que lamió la urna en que iba el corazón de Girardot; los generales, la que tenía en lo apretado de la batalla, cuando la derrota posible endurecía los ojos o se enloquecía de dignidad; los viejos buscarían la de la meditación de Jamaica, aplacada y melancólica. Todos querríamos mirarle, pero habría de saber a quién él querría mirar.. (MISTRAL, 1931, p. 196-197).

Además de mencionar a dos personas muy importantes en la vida de Bolívar - su esposa y el joven y leal soldado Girardot -, Mistral hace una pregunta indirecta en la que deja claro que hay un vacío acerca de quién a él le gustaría mirar, es decir, a quién él respeta en el proceso de liberación en América Latina. Para ello, sería necesario analizar la incompletitud del proyecto bolivariano, es decir, aquello que fue un deseo para él, pero sin el apoyo para concretarlo. En ese sentido, quisiéramos citar las palabras de Kohan que muestran a un pueblo excluido de la liberación latinoamericana incluso habiendo ayudado al Libertador:

Después de Jamaica, Bolívar se dirige a Haití (ya emancipado desde 1804) a pedir ayuda y a entrevistarse con su presidente Alexandre Pétion. El 1/1/1816 llega a Puerto Príncipe. El ejemplo de Haití horrorizaba a todos los colonialistas europeos pero también a los recientemente independizados Estados Unidos, donde trabajan sometidos por la esclavitud más de 1.500.000 esclavos negros. Pétion le brindó a Bolívar, sin condiciones y de modo totalmente generoso, ayuda militar, armas, buques y combatientes. El Libertador lo reconoció sin ambigüedades, llegando a afirmar explícitamente "Pétion es el autor de nuestra libertad" (KOHAN 2013, p. 151-152). 
En las palabras anteriores, es claro que, sin considerar la lucha del pueblo negro en la emancipación latinoamericana, habría un vacío que finalmente haría imposible imaginar la liberación de los indígenas, negros, mestizos y criollos. Pero, la pregunta que queda es: ¿por qué ellos, es decir, el pueblo haitiano, fueron alejados del imaginario histórico de la lucha por la libertad latinoamericana? Antes de aclarar ese punto, hay que afirmar que esta situación representa una de las muchas decepciones que son parte de las arrugas de Bolívar. El contexto es el siguiente:

Esa ayuda haitiana también incidió en el terreno ideológico, contribuyendo a radicalizar el pensamiento político de Bolívar y permitiéndole profundizar la lucha de independencia nacional con todo un arco de demandas sociales entre las cuales la abolición de la esclavitud resultó ser la clave principal. Luego, esa nación que tanto había ayudado a Bolívar no fue aceptada por los políticos de la Gran Colombia para ser invitada al Congreso de Panamá pues preferían no enemistarse con Francia. Francisco de Paula Santander, vicepresidente de Colombia, llegó a decir sobre Haití que "siendo una república de color, traería perjuicios a la causa americana ante opinión de las potencias europeas" (KOHAN, 2013, p.152-153).

Es innegable que Bolívar considera a Haití como los libertadores de América. Sin embargo, son sus aliados los que deciden finalmente excluir a los haitianos del proyecto emancipador. Por un lado, hay una subordinación política a Francia como peligrosa potencia colonizadora y que tiene intereses en Haití. Sin embargo, la razón política más relevante en esta situación y que queda clara en la cita anterior es el racismo de la élite criolla que lideró el proceso revolucionario. Entonces, cuando Mistral se interroga a quien Bolívar quisiera mirar, ella no se equivoca al pensar que hay un vacío en los análisis blancos de la biografía bolivariana. En efecto, Bolívar quisiera mirar y finalmente incorporar a los negros en la historia oficial y en las continuas luchas, incluso en la actualidad, por la emancipación de los pueblos de América.
Aún en las palabras de la Mistral arriba mencionadas, ella busca la mirada bolivariana de la Carta de Jamaica. Es fundamental, a nuestro parecer, comprender el contexto histórico de la carta como punto central para el entendimiento del proyecto de liberación bolivariana. Kohan nos ayuda en esa búsqueda al decir que,

En la Carta Bolívar analiza la guerra social venezolana (desarrollada entre 1812 y 1814) y el papel "insaciable de sangre y crímenes" de los jefes españoles de tropas y las revueltas que los acompañaron y les permitieron vencer a los patriotas. Pensando en todo el continente y su combate contra el colonialismo, rememora la lucha heroica de "los indómitos y libres araucanos". También recuerda a Moctezuma y a Atahualpa, así como la feroz represión que todos ellos sufrieron (KOHAN, 2013, p. 148).

De la misma manera que lo mencionado al comienzo del sub-capítulo sobre las arrugas que vienen desde dentro del cuerpo hasta aparecer en el rostro de Bolívar, en una especie de herencia genética de la experiencia de lucha de muchas generaciones en el pasado y que Bolívar continúa en esta Carta de Jamaica, es preciso hacer un reconocimiento a la memoria histórica de la lucha por la emancipación de los pueblos americanos. Contrario a las metodologías del colonialismo europeo, o el de la letra burguesa republicana latinoamericana del período postcolonial, Bolívar no comienza de cero en su recorrido de la liberación. Él es más una figura de la historia de los Libertadores de América. De ahí que el reconocimiento de grandes referentes de los revolucionarios indígenas sea necesario. Al mismo tiempo, el recuerdo de la libertad de los Araucanos, en forma de mito del origen de América, aclara el hecho de que los pueblos son originalmente libres y no subordinados a sus conquistadores. También, Bolívar lucha por la liberación con furia, es decir, para él la liberación implica lucha y ella debe ser llevada con rabia, producto de ambas consecuencias de la pérdida de libertad y de la violencia que los colonizadores ejercieron para derrocar la emancipación 
de los pueblos de la nación América Latina. Es precisamente esa mirada reflexiva lo referido por Gabriela Mistral.

Sin embargo, referirse a la lucha por la liberación bolivariana como una revolución desordenada sería injusto. En este sentido, hay que mostrar en qué consiste:

Mucho antes de que se pusiera de moda el término "globalización" y cuando Marx, Lenin, o el Che Guevara - propulsores del internacionalismo contemporáneo - aún no habían nacido, Simón Bolívar piensa en una lucha emancipatoria de alcance y aliento internacional. Mirando el mundo en su conjunto, el Libertador se opone a toda dominación colonial y a las maniobras de las grandes potencias europeas y norteamericana. Contra ellas promueve lo que denomina "el equilibrio del mundo", una perspectiva multipolar de la geopolítica internacional. En la Carta de Jamaica Bolívar condensa su mirada estratégica antiimperialista sobre la Patria Grande entendida como "una sola gran nación" y "la más grande nación del mundo", en la cual pueda haber "un solo gobierno que confederase los diferentes estados" (KOHAN, 2013, p.149).

Así, la revolución bolivariana no era simplemente una revolución por la independencia de tipo anárquico para pensar qué sucederá después de la revolución. Ella tiene una clara estrategia de gobierno a priori. Este gobierno incluye a América Latina como un todo, como una "Patria Grande", con un gobierno central y muchos estados autónomos que, a través de la colaboración entre ellos, pueden dar estabilidad a un continente, así como protegerlo de la colonización europea y del expansionismo norteamericano. De ahí que Bolívar sea pionero en aspectos tales como el internacionalismo y la "perspectiva multipolar de la geopolítica internacional".

Luego, Mistral hace referencia a la frente de Bolívar y a las experiencias que esa frente debe haber recibido en la vida del Libertador. Ella, dando características auditivas a una frente, algo entre una personificación, sinestesia y un oxímoron, expresa que "ha oído tristes cosas esta frente de
Bolívar; le han contestado las miserias que sabemos sobre Páez sobre la lealtad." (MISTRAL, 1931, p. 197). Páez, un soldado que alguna vez combatió al lado de Bolívar después se aparta de su lado al no compartir el proyecto geopolítico latinoamericano del Libertador. Entonces, Mistral continúa explicando las tristes experiencias que expresa la frente de Bolívar al decir que,

Esta frente se pone a mirar la tierra de Sudamérica para ver si la han dividido, y allí ella está, todavía hecha provincias, con su poltrón mestizo dueño de la cosecha india; se echa atrás la frente para mirar lejos, y lo que ven son las fronteras que él no quiso y que cada día se cuajan y se enderezan más; a veces, esta frente con ojos intrusos se nos cae encima de nosotros a ver lo que somos, y nos halla celosos como Páez, traicioneros como el negro malo de Jamaica, y sobre todo, lacios del trópico que a él no lo descoyuntó nunca (MISTRAL, 1931, p. 197).

En cuanto a las traiciones, Gabriela Mistral demuestra aparente rabia contra Páez ${ }^{3}$ una vez más y contra los jamaicanos. Sobre el primero, el historiador Kohan, especialista en los procesos revolucionarios latinoamericanos, entrega algunos detalles:

Frente a un avance enemigo Bolívar solicita la ayuda de Páez, pero este contesta con evasivas. Era muy valiente pero su perspectiva era limitada. A Bolívar le tocó entonces enfrentar a Morillo sin contar con Páez. Como recuerda Juvenal Herrera Torres, la defección de Páez había desbaratado los planes y deseos del Libertador. Monagas y Zaraza habían sido derrotados por Morales y no quedaba otra alternativa a los republicanos que huir nuevamente hacia el llano profundo. En medio de la lluvia y los relámpagos, los patriotas tomaron la vía escabrosa que lleva por nombre Cuesta de la Muerte para organizar la retirada (KOHAN, 2013, p.178).

${ }^{3}$ Páez, representante de los defensores independentistas más humildes, ayuda a Bolívar en muchas batallas tales como "Las Queseras del Medio" y de Carabobo. Bolívar hasta lo condecora cona "Orden de los Libertadores" Sin embargo "a nivel político, Páez muchas veces privilegió sus conflictos "Oring e intereses domésticos e locales, sin poder ver el panorama continental e los planes estratégicos del
Libertador" (KOHAN, 2013, p.175). 
Ello llevó al ejército republicano finalmente a su aniquilación en manos de los soldados españoles liderados por Morillo. De ahí que la traición de Páez sea tan triste y decepcionante en la liberación bolivariana en América Latina. El proyecto reactivo de Páez, el cual consistía en defender su propia localidad sin pensar en el sentido global de la emancipación de los pueblos latinoamericanos, desde una perspectiva egoísta y de tipo nacionalista, es algo que claramente Mistral, otra profunda latinoamericanista no logra perdonar. En el caso de la traición de Jamaica, sucede que cuando él estuvo allí, es mal recibido y vive en completa miseria. Se queda sin dinero para pagar el alquiler y hasta debe huir de un intento de asesinato en su contra (Kohan, 2013). No obstante aquello, es precisamente en ese lugar en el cual escribe la Carta Fundamental de sus principios libertadores.

En la cita anterior, Gabriela Mistral dice que la Gran Patria todavía está pendiente porque aún existe división entre los pueblos que pertenecen a América Latina. En ese sentido, sería interesante revisar que, aunque el proyecto de la Patria Grande como tal se establece en la Carta de Jamaica, la reflexión en torno a la división de los pueblos ocurre en la Carta de Cartagena. Al respecto, Kohan afirma:

... Bolívar pone en discusión el sistema federal alegando que en los inicios de una nueva república se torna necesaria una centralización política. (...) El principal corolario teórico del Manifiesto de Cartagena afirma que "Pero lo que más debilitó más al gobierno de Venezuela fue la forma federal que adoptó [...] Nuestra división y no las armas españolas nos tornó a la esclavitud." De allí en más y durante toda su vida, será un tenaz partidario de la unidad popular, como núcleo de acero de una fuerza combatiente emancipadora (KOHAN, 2013, p. 124).

En la reflexión anterior, es patente que la división y la emancipación no son sinónimos y que el establecimiento de un gobierno de tipo federal en las naciones latinoamericanas es un proyecto contrarrevolucionario.
Sin embargo, la división es permanente del mismo modo en que las luchas deben ser permanentes mientras la emancipación no suceda en su totalidad. Mistral habla al respecto al hacer un llamado a nosotros para que,

Hagámosle criatura cotidiana mejor que nombre de aniversario, vivámosle en la permanencia y no sólo en las lentas puntadas de los centenarios.

Vivámosle en la continuidad como se vive una ley; pongámonos a tenerlo por paisaje nuestro, hasta que nos corra la sangre hecho la masa de nuestra sangre (MISTRAL, 1931, p. 199).

De la misma manera que es mejor considerar Bolívar un héroe en vez de un santo, es mejor hacer su revolución diaria. El precio de la revolución es la sangre, en doble sentido, en tanto pasión y como resultado de la lucha por la liberación. Mistral sabía claramente la diferencia entre la liberación de Bolívar y el liberalismo del Norte. Para evitar generar confusiones que puedan alejarnos del camino bolivariano, el texto abajo no deja ninguna duda:

(Simón Bolívar) defendió la democracia y "el santo dogma de la igualdad" criticando a los liberales. De ellos llegó a decir que: "Tales son nuestros liberales: crueles, sanguinarios, frenéticos, intolerantes y cubriendo sus crímenes con la palabra libertad que no temen profanar".

El proyecto libertario de Simón Bolívar resulta profundamente distinto del liberalismo (...) afirma “ ¿Hay mejor medio de alcanzar la libertad que luchar por ella?". No reduce mecánicamente la libertad ni a los procedimientos formales de repúblicas elitistas, oligárquicas y antipopulares ni a la letra muerta de la ley escrita, como habitualmente han hecho en nuestro continente un ejército de abogados, juristas y leguleyos. De allí que escriba "Tengo mil veces más fe en el pueblo que en sus diputados" (KOHAN, 2013, p. 165).

Mistral sabía que la liberación bolivariana era una revolución por la verdadera libertad de pueblos subordinados a la colonización europea y 
que el liberalismo norteamericano era una falsa promesa de libertad con el resultado de una neo-colonización producto de expansionismo y, como consecuencia, con la subordinación de los latinoamericanos una vez más. En este sentido, Mistral no se equivoca al hablar y confirmar las palabras de Bolívar de que la guerra garantiza la libertad. De ahí que la sangre sea el símbolo de la lucha por la liberación y emancipación de Bolívar.

Gabriela Mistral es consciente de ello y no teme seguirla y hacer un llamado a otros a ser parte de esta lucha también.

\section{Consideraciones finales}

El hecho de Mistral sea mujer y educadora, ayuda bastante en el proceso de normalización al que ella debía responder. También ayuda el hecho de que salga de Chile, a causa del continuo acoso del que es víctima en la mayoría de los lugares en los que vive y trabaja. Debido a lo anterior, la República de Chile crea un mito sobre Gabriela Mistral, con el objetivo de colonizar tanto su figura como su producción en el imaginario colectivo del país. Desde ahora, la otrora mujer contestataria y de origen humilde y campesino, se convertía en la madre de Chile, una figura conservadora y obediente a los valores republicanos. Al mismo tiempo, dejaba de ser un puente entre el resto de las personas y la posibilidad de acceso a una cultura igualitaria para todos y todas. Desde ese momento, se convierte en una figura de excepción, la cual, por sus cualidades extraordinarias, logra entrar en un mundo letrado difícil de ser alcanzado. De ese momento, se establece una censura de la obra de la autora y sólo se considera parte de su producción con el objetivo de crear una narrativa sobre su vida y pensamiento, la cual se mantiene hasta hoy en el imaginario colectivo chileno. Sin embargo, Mistral continuaba ejerciendo su derecho escritural en otros países de América Latina y del mundo. Gracias a ello, hay en la actualidad un rico acervo literario, no sólo de su producción poética sino también de sus contribuciones prosaicas, las cuales incluyen numerosas prosas políticas por ella presentadas en revistas y conferencias. De ahí que aquello que no fuere escogido por la historiografía oficial o por la crítica literaria tradicional y pueda ser rescatado gracias al ejercicio de la memoria en la actualización de su archivo. Sólo esa memoria hace y continuará haciendo justicia al archivo de Gabriela Mistral.

La reivindicación de la memoria de Gabriela Mistral derriba el mito colonial sobre ella creado en el Chile Republicano. Por este motivo, para hacer esta reivindicación, en esta investigación decidimos descolonizar ese mito gracias al reconocimiento del mito de origen de nuestra autora, el cual se vincula no sólo a su obra sino a la relación dialógica de esa obra con la reivindicación de los pueblos latinos e hispanos de los cuales forma parte. Y en esa lucha por la liberación de los pueblos de Bolívar, y de la cual Mistral es una fiel seguidora e impulsora, es posible alcanzar una cultura democrática que garantice la emancipación de hombres y mujeres en un espacio republicano ético. Lo anterior es una realidad en la consideración íntegra del sintagma literatura y política encarnado en la prosa de Gabriela Mistral. Es ese discurso el que ocurre en una relación de intersubjetividad solidaria en la que hacemos justicia tanto para Gabriela Mistral como para todos nosotros (lo cual incluye a todos - escritores, poetas, indígenas, campesinos, obreros, personas fuera de la Capital de Chile, Santiago, entre otros seres subalternos que hoy, gracias a Gabriela Mistral, poseen acceso al mundo literario en el espacio público).

Así, nosotros hacemos justicia de ella en la misma consideración de un Premio Nobel de Literatura para América Latina cuya escritura es tan relevante para nuestra cultura desde su contribución literaria como desde su valor político en nuestro recorrido por la descolonización de su nombre y de nuestra cultura original, independiente y libre. 


\section{Referencias}

BAKHTIN, Mikhail. Questões de literatura e de estética (A teoria do romance). Trad. Aurora Fornoni Bernardini et al. São Paulo: HUCITEC, 2010.

BAKHTIN, Mikhail. Estética da criação verbal. Trad. Paulo Bezerra. São Paulo: Martins Fontes, 2011.

BEMONG, Nele; BORGHART, Pieter. A teoria bakhtiniana do cronotopo literário. In: BEMONG, Nele; et al. Bakhtin e o cronotopo: reflexões, aplicações e perspectivas. Trad. Ozíris Borges Filho et al. São Paulo: Parábola Editorial, 2015.

FARACO, Carlos Alberto. Linguagem \& Diálogo: As ideias linguísticas do Círculo de Bakhtin. São Paulo: Parábola, 2017.

FIORIN, José Luiz. Introdução ao pensamento de Bakhtin. São Paulo: Contexto, 2017.

KOHAN, Néstor. Simón Bolívar y nuestra independencia: una lectura latinoamericana. Amauta Insurgente Ediciones; Yulca Editorial; Ediciones La Llamarada, 2013.

MISTRAL, Gabriela. (1925). Organización de las mujeres. In: DEL POZO, Diego. Por la humanidad futura: antología política de Gabriela Mistral. La Pollera Ediciones, 2015.

MISTRAL, Gabriela. (1931). Bolívar (I). In: QUEZADA, Jaime. Gabriela Mistral: escritos políticos. Fondo de Cultura Económico, México, 1994.

MISTRAL, Gabriela. (1931). Bolívar (II). In: QUEZADA, Jaime. Gabriela Mistral: escritos políticos. Fondo de Cultura Económico, México, 1994.

QUEZADA, Jaime. Gabriela Mistral: escritos políticos. Fondo de Cultura Económica, Santiago, 1994.

Recebido em 30/06/2018

Aceito em $10 / 12 / 2018$ 